\title{
Cutaneous Rhinosporidiosis Mimicking Soft Tissue Tumour: A Case report with Review of Literature
}

\author{
Pallavi Agrawal', Richa Bhartiya ${ }^{1 *}$ and Rakesh Mehra $^{2}$
}

${ }^{1}$ Department of Pathology, Patna Medical College Hospital (PMCH), Ashok Rajpath, Patna(Bihar), India

${ }^{2}$ Department of Radiology, Patna Medical College \& Hospital (PMCH), Ashok Rajpath, Patna(Bihar), India

\section{ABSTRACT}

Objective: Rhinosporidiosis is a chronic granulomatous disease caused by Rhinosporidium seeberi. It is endemic in India \& Sri Lanka. It usually involves the nasal cavity \& rarely other sites including skin. Cutaneous rhinosporidiosis presents as papule \& nodule and very rarely as soft tissue mass.

Case Report: We report a case of cutaneous rhinosporidiosis in a 32-year old HIV seropositive male presenting as soft tissue mass on lateral aspect of left foot near ankle-joint.

Conclusion: High index of suspicion is very important for an early diagnosis and management of these cases. Rarity of this lesion warrants its mention.

Keywords: Rhinosporidium Seeberi, Subcutaneous, Nasal Cavity

\section{Introduction}

Rhinosporidiosis is a chronic granulomatous disease caused by Rhinosporidium seeberi ${ }^{[1]}$ It is endemic in India and Sri Lanka but has also been reported from United states, South America and Iran. In India, it is found more commonly in southern and central regions. ${ }^{[2]}$ It usually involves nasal cavity but may rarely involve the lips, palate, uvula, maxillary antrum, epiglottis, larynx, trachea, bronchus, ear, scalp, vulva, vagina, penis, rectum and the skin. ${ }^{[3]}$ Cutaneous rhinosporidiosis is a well known entity as most patients present with warty papule and nodule but cutaneous rhinosporidiosis mimicking clinically as soft tissue tumour is very rare. Only few such cases with tumoral presentations are reported in literature, however, their HIV status and geographic locale is not known. ${ }^{[4-9]}$ We report a HIV seropositive case of cutaneous rhinosporidiosis in a 32-year-old male with brief review of literature regarding this rare presentation, and discuss the etiologic agent, pathogenesis and treatment of such cases.

\section{Case Report}

A 32-year-old male presented with a gradually progressive swelling over the lateral aspect of left foot near ankle joint for one year. He had not received any prior treatment for this swelling. Now the patient sought medical attention for recent onset of pain and difficulty in walking for one month duration. On examination, a firm, non-tender, irregular swelling measuring $7 \times 5 \mathrm{~cm}$ was found on lateral aspect of left ankle joint. The overlying skin was erythmatous, shiny with several prominent dilated veins. No ulceration was identified (Fig 1). No other verrucous lesion or cutaneous nodules could be identified. There was no regional lymphadenopathy. On anterior rhinoscopy no growth was identified in the bilateral nasal cavities. His serology for HIV infection by ELISA was positive. On radiological examination the underlying bone was free from the mass and the proximal tibia and fibula were unaffected. The patient was admitted with a differential diagnosis of squamous cell carcinoma vs soft tissue sarcoma. An excision biopsy of the mass was performed. Microscopic examination revealed numerous globular cysts of varying size. Thick walled sporangia could be identified containing numerous endospores. Also seen were trophocytes in various stages of development. The tissue between the cysts shows foreign body type of giant cell reaction and inflammatory infiltrate chiefly composed of plasma cells, lymphocytes, macrophages and few neutrophils (Fig 2). There were fresh and organizing thrombi in adjacent areas. The refractile sporangial wall and the cell walls of mature spores could be well highlighted on post-diastase Periodic Acid-Schiff stain (PAS). Trophocytes, immature spores and sporangia were weakly positive for PAS. The GrocottGomori methenamine silver method stained the sporangial wall uniformly black and outlined mature spores in the sporangia. Ziehl-Neelsen stain could not demonstrate any acid-fast bacilli. Based on morphology a diagnosis of 
Rhinosporidiosis was given. On further enquiry he gave a history of having undergone excision of nasal mass 20 years ago. Unfortunately, no histopathological records were available. Though Rhinosporidiosis responds well to chemotherapy but discomfort caused by massive lesion necessitates surgical excision. The patient was lost to follow up before complete surgical excision could be done. For the same reason other therapies could also be not given. Though the patient was seropositive for HIV, there was no other evidence of immunodeficiency, clinically or by other parameters.

\section{Discussion}

Rhinosporidiosis is a chronic granulomatous disease first described by Guillermo Seeber, in 1896 who considered the sporangium of R. seeberi to be a sporozoan similar to coccidian. Though the agent was considered a fungus it was interpreted as a protozoan parasite, a cyanobacterium, and a carbohydrate waste product. ${ }^{[3]}$ Although the taxonomy is controversial but recent biological and organism's ribosomal DNA analysis suggest that R. seeberi is not a fungus but a protist belonging to Mesomycetozoa, which is located phylogenetically between the fungal and animal divergence. ${ }^{[10]}$ Cutaneous rhinosporidiosis was initially described by Forsyth. ${ }^{[11]}$ It usually affects males (70-90\%) with a greater incidence in those aged between 20 and 40 years. ${ }^{[3]}$ It is transmitted to humans by direct contact with spores through dust, through infected clothing or finger and bathing in stagnant water. Rhinosporidiosis frequently involves nasopharynx (70\%) presenting

Table 1: Summary of cases of tumoral cutaneous rhinosporidiosis.

\begin{tabular}{|l|c|c|c|c|c|c|}
\hline Author & Year & Age (yrs) & Sex & Clinical presentation & Clinical diagnosis & Histopathological examination \\
\hline Aravindan et al[4] & 1989 & 60 & $\mathrm{M}$ & Left scapular mass & Chondrosarcoma & Rhinosporidiosis \\
\hline Angunawela et al[5] & 1999 & 44 & $\mathrm{M}$ & $\begin{array}{c}\text { Thigh and anterior } \\
\text { chest wall mass with } \\
\text { nasal polyps }\end{array}$ & Soft tissue sarcoma & Rhinosporidiosis \\
\hline Date et al[6] & 1995 & 30 & $\mathrm{~F}$ & Right thigh mass & Soft tissue sarcoma & Rhinosporidiosis \\
\hline Houreih et al[ ${ }^{[7]}$ & 2006 & 39 & $\mathrm{M}$ & Popliteal fossa mass & Soft tissue sarcoma & Rhinosporidiosis \\
\hline Avadhani et al[8] & 2008 & 57 & $\mathrm{M}$ & Swelling right leg & Soft tissue sarcoma & Rhinosporidiosis \\
\hline Prasad et al ${ }^{[9]}$ & 2015 & 71 & $\mathrm{M}$ & Right thigh mass & Soft tissue sacoma & Rhinosporidiosis \\
\hline Index case & 2015 & 32 & $\mathrm{M}$ & Swelling left foot & $\begin{array}{c}\text { Soft tissue sarcoma/ } \\
\text { Squamous cell } \\
\text { carcinoma }\end{array}$ & Rhinosporidiosis \\
\hline
\end{tabular}

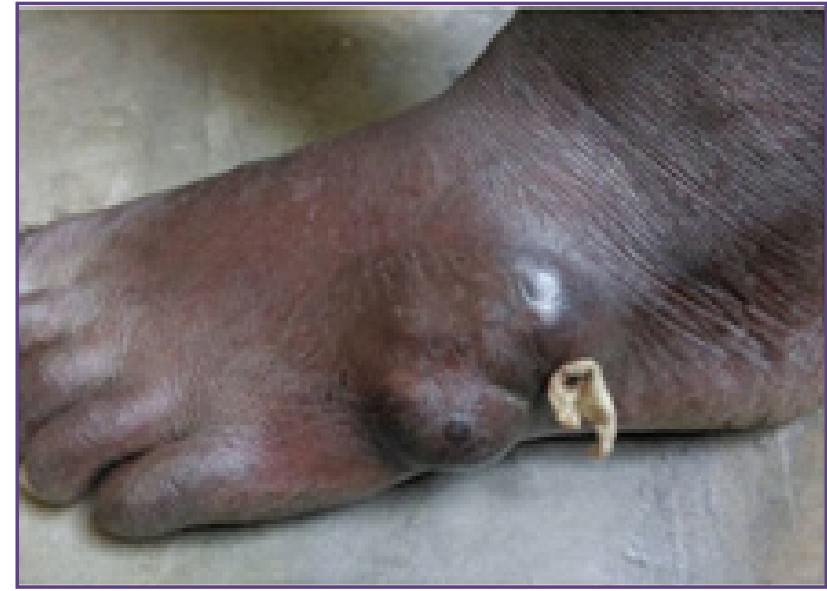

Fig. 1: Soft tissue swelling on lateral aspect of left foot near ankle-joint.

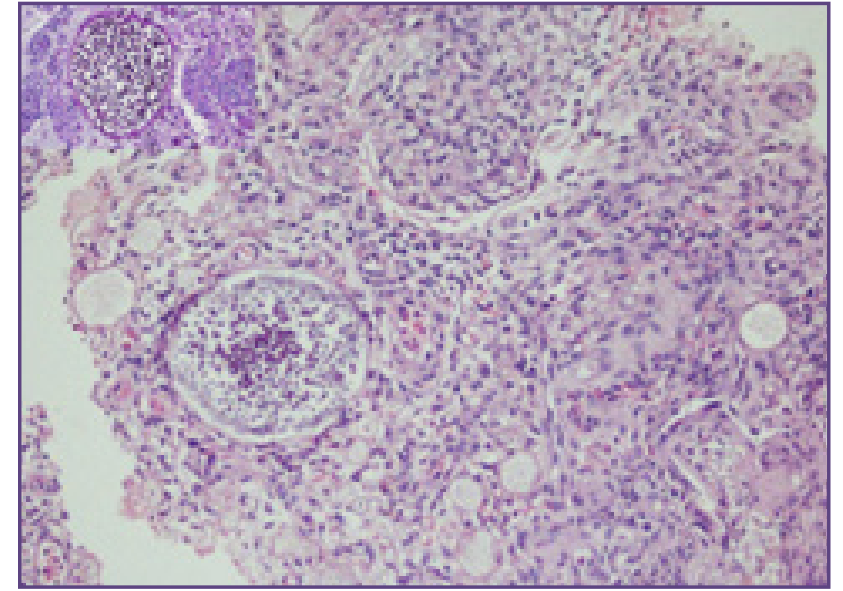

Fig. 2: Photomicrograph of rhinosporidiosis showing sporangium containing many individual spores ( $\mathrm{HxE} \times 200)$. Inset shows PAS stained spores at high power ( $\mathrm{x} 400)$. 
as painless, polypoidal, pink or purple friable growth studded with minute white dots, which are sporangia containing the spores. Nasal obstruction and bleeding are most common symptoms. Cutaneous rhinosporidiosis may present as 1) satellite lesions, in which skin adjacent to the nasal rhinosporidiosis is involved secondarily 2) generalized cutaneous type with or without nasal involvement, due to hematogenous dissemination of the organism; and 3) primary cutaneous type associated with direct inoculation of organisms in the skin. ${ }^{[12]}$ Most of the reported cases of cutaneous rhinosporidiosis presented with multiple warty lesions or subcutaneous nodules with or without nasal involvement but tumoral cutaneous rhinosporidiosis is very rare. Only few cases have been reported in literature so far (Table-1). Date et al proposed the term rhinosporidioma to such tumoral cutaneous rhinosporidiosis. ${ }^{[6]}$ It is possible that the nasal mass removed 20 years back was rhinosporidiosis with seeding of the soft tissue at that time. Autoinoculation could be mode of spread. The infection was probably smoldering and gradually progressed to the current size.Microscopic examination shows mycotic elements consisting of sharply defined globular thick-walled cysts (sporangia), upto $0.5 \mathrm{~mm}$ in diameter, which contain numerous rounded endospores, 6-7 $\mu$ in diameter. Immature and collapsed sporangia are also present. Epithelioid granulomatous reaction may accompany the organisms along with fibroblasts and endothelial cells. The life cycle of the parasite is complicated. The mature forms of the organism, known as sporangia, contain multiple sporangiospores. The trophocytes, the immature forms of R. seeberi, are smaller and thinner than sporangia and do not contain endospores. Sporangiospores are released at maturity and thereafter develop into trophocytes. Wart like cutaneous lesion of rhinosporidiosis generally ulcerate. These ulcerated lesions have to be distinguished from squamous cell carcinoma, basal cell carcinoma, verruca vulgaris, tuberculosis verrucosa cutis, granuloma pyogenicum, veneral warts and donovanosis. ${ }^{[13]}$ This disease must also be differentiated from coccidiomycosis which has a different clinical presentation and smaller fungal spherules $(30-60 \mu \mathrm{m})$. The immature centralnuclear form is not seen and the endospores have a simpler structure $(2-5 \mu \mathrm{m}){ }^{[1]} \mathrm{R}$. seeberi grows in cell culture but cannot be isolated in synthetic media. Some recent studies stressed on the need of fine needle aspiration cytology in these cases ${ }^{[14]}$ But histopathology remains the mainstay in providing definitive diagnosis of Rhinosporidiosis. Development of a cutaneous lesion should be considered as indication of early dissemination and meticulous search should be made to exclude systemic involvement. ${ }^{[15]}$ Surgical removal and electrodesiccation are the treatments of choice. Various drugs like dapsone, ketoconazole and ciprofloxacin have been suggested which may arrest the maturation of sporangia and accelerate degenerative changes in them. The organisms are then removed by an accelerated granulomatous response. ${ }^{[12]}$

\section{Conclusion}

The present case is reported to highlight the fact that cutaneous rhinosporidiosis apart from warty and nodular lesions can also present as large soft tissue masses clinically mimicking soft tissue tumour so a high degree of clinical suspicion is very important for early diagnosis and prompt management of such cases.

\section{Reference}

1. Chung KG, Bennett JE. Medical mycology. London: Philadelphia,Lea \& Febiger 1992:695-704

2. Grover S. Rhinosporidiosis. J Ind Med Assoc 1975;64:93-95

3. Lupi O, Tyring SK McGinnis MR. Tropical dermatology: Fungal tropical diseases. J Am Acad Dermatol 2005;53:931-51

4. Aravindan KP, Viswanathan MK, Jose L. Rhinosporidioma of bone. A case report. Indian J.Pathol. Microbiol. $1989 ; 32: 312-13$

5. Angunawela P, Tissera AD, Dissanaike AS. Rhinisporidiosis presenting with two soft tissue tumors followed by dissemination. Pathology 1999;31:57-58

6. Date A, Ramakrishna B, Lee VN, Sundararaj GD. Tumoral rhinosporidiosis. Histopathology 1995;27:288-90

7. Houreih MA, Eyden B, Lucas SB, et al. Rhinosporidium seeberi: a case clinically mimicking soft tissue sarcoma. Histopathology 2006;49:208-210

8. Avadhani A, Pai K, Mohanty SP. Cutaneous rhinosporidiosis clinically masquerading as a soft tissue sarcoma- a rare occurrence. International J of Dermatol 2008;47:1153-54

9. Prasad HLK, Rao C, Girisha BS, et al. Subcutaneous Rhinosporidiosis masquerading as soft tissue tumour: Diagnozed by Fine Needle Aspiration Cytology. Indian J Dermatol. 2015;60(2):215

10. Herr RA, Ajello L, Taylor JW, et al. Phylogenetic analysis of rhinosporidiosis seeberi's $18 \mathrm{~S}$ small-subunit ribosomal DNA groups this pathogen among members of the protoctistan Mesomycetozoa clade. J Clin Microbiol $1999 ; 37: 2750-54$ 
11. Padmavathy L, Rao IL, Sevam SS, et al. Disseminated cutaneous rhinosporidiosis in a HIV seropositive patient. Indian J Dermatol Venerol Leprol 2001;67:332-333

12. Kumari R, Laxmisha C, Thappa DM. Disseminated cutaneous rhinosporidiosis. Dermatol Online J 2005;11:19

13. Kamal MM, Luley AS, Mundhada SG, Bobhate SK. Rhinosporidiosis. Diagnosis by scrape cytology. Acta cytol 1995;39:931-35
14. Mandol, Kumar $\mathrm{P}$ et al. Disseminated Cutaneous Rhinosporidiosis: a Tumour like lesion with Therapeutic challenge. Indian Journal of Pathology. 2014;9(4):

15. Gayathri P RS, Srinivasa Kannan SR, Parijatham BO, Ganapathy H, Subhashree AR. A rare case of disseminated cutaneous rhinosporidiosis. Journal of Clinical and Diagnostic Research 2015 Jan, Vol-9(1): EL01-EL02

*Corresponding author:

Dr Richa Bhartiya, \% Shri Vinay Kumar Shrivastava, Dy. CSTE, Bungalow No. 882, Railway Officers' Colony, Danapur (KHAGAUL),

Patna (Bihar)- 801105, , Bihar, India

Email: richabhartiya1972@gmail.com

Date of Submission : 03.12.2016

Date of Acceptance : 14.04.2017

Financial or other Competing Interests: None.

Date of Publication : 25.08.2017 